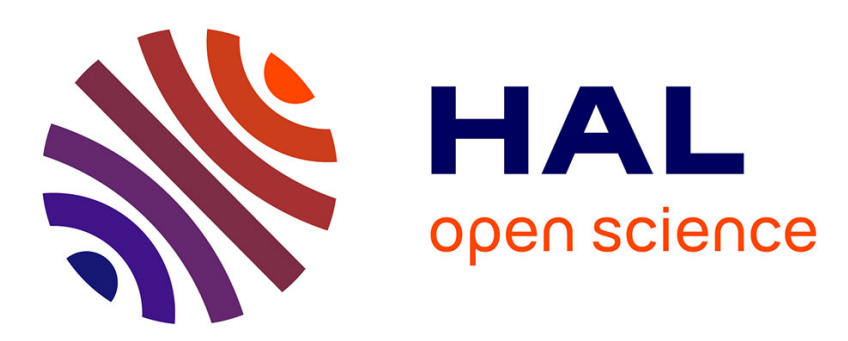

\title{
Mesoporous binder-free monoliths of few-walled carbon nanotubes by spark plasma sintering
}

\author{
Christophe Laurent, Ty Mai Dinh, Marie-Claire Barthélémy, Geoffroy \\ Chevallier, Alicia Weibel
}

\section{- To cite this version:}

Christophe Laurent, Ty Mai Dinh, Marie-Claire Barthélémy, Geoffroy Chevallier, Alicia Weibel. Mesoporous binder-free monoliths of few-walled carbon nanotubes by spark plasma sintering. Journal of Materials Science, 2018, vol. 53 ( $\mathrm{n}^{\circ}$ 5), pp. 3225-3238. 10.1007/s10853-017-1784-0 . hal-01682484

\section{HAL Id: hal-01682484 \\ https://hal.science/hal-01682484}

Submitted on 12 Jan 2018

HAL is a multi-disciplinary open access archive for the deposit and dissemination of scientific research documents, whether they are published or not. The documents may come from teaching and research institutions in France or abroad, or from public or private research centers.
L'archive ouverte pluridisciplinaire HAL, est destinée au dépôt et à la diffusion de documents scientifiques de niveau recherche, publiés ou non, émanant des établissements d'enseignement et de recherche français ou étrangers, des laboratoires publics ou privés. 


\section{Open Archive TOULOUSE Archive Ouverte (OATAO)}

OATAO is an open access repository that collects the work of Toulouse researchers and makes it freely available over the web where possible.

This is an author-deposited version published in : http://oatao.univ-toulouse.fr/ Eprints ID : 19430

To link to this article : DOI:10.1007/s10853-017-1784-0

URL : http://dx.doi.org/10.1007/s10853-017-1784-0

To cite this version : Laurent, Christophe $\leftrightarrows$ and Dinh, Ty Mai Barthélémy, Marie-Claire Alicia nanotubes by spark plasma sintering. (2018) Journal of Materials Science, vol. 53 ( $\mathrm{n}^{\circ}$ 5). pp. 3225-3238. ISSN 0022-2461

Any correspondence concerning this service should be sent to the repository administrator: staff-oatao@,listes-diff.inp-toulouse.fr 


\title{
Mesoporous binder-free monoliths of few-walled carbon nanotubes by spark plasma sintering
}

\author{
Ch. Laurent ${ }^{1, \star}$, T. M. Dinh ${ }^{1}$, M.-C. Barthélémy ${ }^{1}$, G. Chevallier $^{1,2}$, and A. Weibel ${ }^{1}$ \\ ${ }^{1}$ Université de Toulouse, CIRIMAT, CNRS-INPT-UPS, Université Paul-Sabatier, 118 Route de Narbonne, 31062 Toulouse Cedex 9, \\ France \\ 2 Plateforme Nationale CNRS de Frittage Flash, PNF2, MHT, Université Paul-Sabatier, 118 Route de Narbonne, \\ 31062 Toulouse Cedex 9, France
}

\begin{abstract}
Carbon nanotubes with few walls (FWCNTs) are prepared by catalytic chemical vapor deposition. Transmission electron microscopy investigations for each sample show the average number of walls $(3,4$ and 8$)$ as well as the internal and external diameter distributions. Binder-free FWCNT monoliths are prepared by spark plasma sintering (SPS) at temperatures in the range $1000-1600{ }^{\circ} \mathrm{C}$. A combination of techniques including Raman spectroscopy, scanning- and transmission electron microscopy, electron microdiffraction is used to characterize the samples. Compared to the FWCNT powders, the high temperatures used for SPS favor the elimination of surface defects in CNT walls but also some limited amorphization, without dramatic damage to the CNTs. Increasing the SPS temperatures produces an increase in densification. $\mathrm{N}_{2}$ adsorption-desorption cycles revealed that the powders and monoliths show microporosity and, mostly, mesoporosity. Some monoliths show a specific surface area equal to about $500 \mathrm{~m}^{2} / \mathrm{g}$. The 4 WCNTs when consolidated into monoliths by SPS at 1000 or $1100{ }^{\circ} \mathrm{C}$ are able to retain a high amount of mesoporosity that contributes to a high porous volume of the order of $0.8 \mathrm{~cm}^{3} / \mathrm{g}$.
\end{abstract}

\section{Introduction}

Carbon nanotube (CNT) monoliths (also denoted as CNT compacts) are attracting much interest because they may have exceptional physical [1-7] and mechanical properties [8-13]. They may present some meso- and macro-porosity [14-16] and are considered biocompatible [11, 12]. To the best of our knowledge, all reported works are performed on multi-walled
CNTs (MWCNTs) with outer diameters typically in the range $10-50 \mathrm{~nm}$, corresponding to CNTs with about 10-50 walls [17], except one report using single-wall CNTs (SWCNTs) [10] and one using doublewalled CNTs (DWCNTs) [15]. Few-walled carbon nanotubes (FWCNTs) have 3-6 walls (some authors [18] also include the DWCNTs) and show both the high aspect ratio of SWCNTs and DWCNTs and the robustness of MWCNTs while containing less 
structural defects than the latter, making them interesting for many applications [18-22]. The aim of the present paper is to prepare binder-free FWCNTs monoliths by spark plasma sintering and to investigate the density, presence of defects and porosity. Some monoliths show a specific surface area about $500 \mathrm{~m}^{2} / \mathrm{g}$ as well as micro- and mesoporosity and high porous volume.

\section{Materials and methods}

\section{Carbon nanotubes}

The FWCNTs were synthesized by a catalytic chemical vapor deposition (CCVD) route described elsewhere [23, 24]. First, two oxide powders were prepared, the formulas of which are written as $\mathrm{Mg}_{0.99}\left(\mathrm{Co}_{0.33} \mathrm{Mo}_{0.67}\right)_{0.01}$ and $\mathrm{Mg}_{0.90}\left(\mathrm{Co}_{0.33} \mathrm{Mo}_{0.67}\right)_{0.10}$ for commodity and are denoted powders A and B, respectively. Indeed, free $\mathrm{MoO}_{3}$ particles are present because the molybdenum ions do not enter the rock salt lattice of $\mathrm{MgO}$. Powders A and B were submitted to a CCVD treatment $\left(\mathrm{H}_{2}-\mathrm{CH}_{4}\right.$ with 18 and $36 \mathrm{~mol} \%$ $\mathrm{CH}_{4}$, respectively, heating and cooling rates $5{ }^{\circ} \mathrm{C}$ $\min ^{-1}$, maximum temperature $1000^{\circ} \mathrm{C}$, no dwell). This produced $\mathrm{CNT}-\mathrm{Co}-\mathrm{Mo}_{2} \mathrm{C}-\mathrm{MgO}$, denoted powders $\mathrm{AR}$ and $\mathrm{BR}$, respectively, which were soaked in a $37 \% \mathrm{HCl}$ aqueous solution in order to dissolve $\mathrm{MgO}$ as well as unprotected $\mathrm{Co}$ and $\mathrm{Mo}_{2} \mathrm{C}$ particle [25]. Indeed, previous studies [26, 27] have shown that unlike nitric acid or other oxidizing acids, $\mathrm{HCl}$ does not damage the CNTs (no opening of the CNTs, no oxidation of the tips and defects which may be present on the outer sidewalls). The acidic suspensions were filtered on $0.45 \mathrm{~mm}$ pore size cellulose nitrate membranes (Whatman) and washed with deionised water until neutrality and subsequently filtered and washed with ethanol. Finally, the samples were dried overnight at $80{ }^{\circ} \mathrm{C}$ in air. The CNT powders derived from the A and B powders will be denoted 3WCNT and 4WCNT hereafter, respectively, denoting the average number of walls $(\mathrm{N})$ as discussed later in the text. For the sake of comparison, an MWCNT powder was purchased from Nanocyl (Belgium). It was prepared using a CCVD route but the precise experimental details are not known to the authors. A previous study [28] revealed that $\mathrm{N}$ is equal to 8 and therefore the MWCNT sample will be denoted 8 WCNT hereafter.

\section{Spark plasma sintering}

The CNT powders were divided into several batches, which were consolidated by spark plasma sintering (SPS, Dr Sinter 2080, SPS Syntex Inc., Japan). They were loaded into a 8-mm inner diameter graphite die. A sheet of graphitic paper was placed between the punch and the powder as well as between the die and the powder for easy removal. The powders were sintered in vacuum (residual cell pressure $<10 \mathrm{~Pa}$ ). A pulse pattern of twelve current pulses followed by two periods of zero current was used. A heating rate of $300{ }^{\circ} \mathrm{C} / \mathrm{min}$ was used from room temperature to $600{ }^{\circ} \mathrm{C}$, where a 1-min dwell was applied. A uniaxial charge was gradually applied during the ramp and dwell, reaching a value corresponding to $100 \mathrm{MPa}$ on the pellet. Then, the temperature was raised $\left(100{ }^{\circ} \mathrm{C} /\right.$ min) to a maximum in the range $1000-1600{ }^{\circ} \mathrm{C}$, as required for the study, where a 3-min dwell was applied. An optical pyrometer, focused on a little hole at the outer surface of the die, was used to control the temperature. Natural cooling was applied down to room temperature, and the uniaxial load was gradually released during the same time. The sintered specimens were in the form of pellets $8 \mathrm{~mm}$ in diameter and about $2 \mathrm{~mm}$ thick. The sintered specimens will be noted as in the following example: $3 \mathrm{~W} 1100,3 \mathrm{~W}$ indicating that the 3WCNT powder was used and 1100 denoting a SPS temperature equal to $1100{ }^{\circ} \mathrm{C}$.

\section{Characterization}

The composite powders and CNT samples were observed by field-emission gun scanning electron microscopy (FESEM, JEOL JSM 6700F) and transmission electron microscopy (TEM, JEOL JSM 2100F operated at $200 \mathrm{kV}$ ). The carbon content in the CNT powders was determined by flash combustion. $\mathrm{N}_{2}$ adsorption-desorption isotherms of the CNT powders and monoliths were measured at liquid- $\mathrm{N}_{2}$ temperature (Micromeritics ASAP 2020). The samples were previously degassed by heating at $120{ }^{\circ} \mathrm{C}$ under a primary vacuum for $12 \mathrm{~h}$. Specific surface areas $\left(\mathrm{S}_{\mathrm{BET}}\right)$ were calculated using the BET equation. Pore size distributions were calculated from the desorption branch using the non-local density functional theory (NLDFT) kernel in the MicroActive 3.00 software. Selected samples were studied by Raman spectroscopy (Jobin-Yvon LabRAM HR800 
spectrometer using the $633 \mathrm{~nm}$ laser excitation). The density of the pellets was calculated from their weight and dimensions. A selected monolith was observed by FESEM and TEM. Focused Ion Beam (FIB) FESEM (FEI Helios 600i) was used for the preparation of a cross-sectional foil of the monolith for TEM observations. Prior to cutting with a focused $\mathrm{Ga}^{+}$ions beam (maximum current $65 \mathrm{nA}$ ), a strip of $\mathrm{Pt}$ was deposited above the area of interest in order to protect it from ablation and Ga-implantation during preparation. Energy-dispersive X-ray spectroscopy (EDS, Bruker Silicon drift detector (SDD) with a resolution of $127 \mathrm{eV}$ ) and electron microdiffraction were performed during TEM observations.
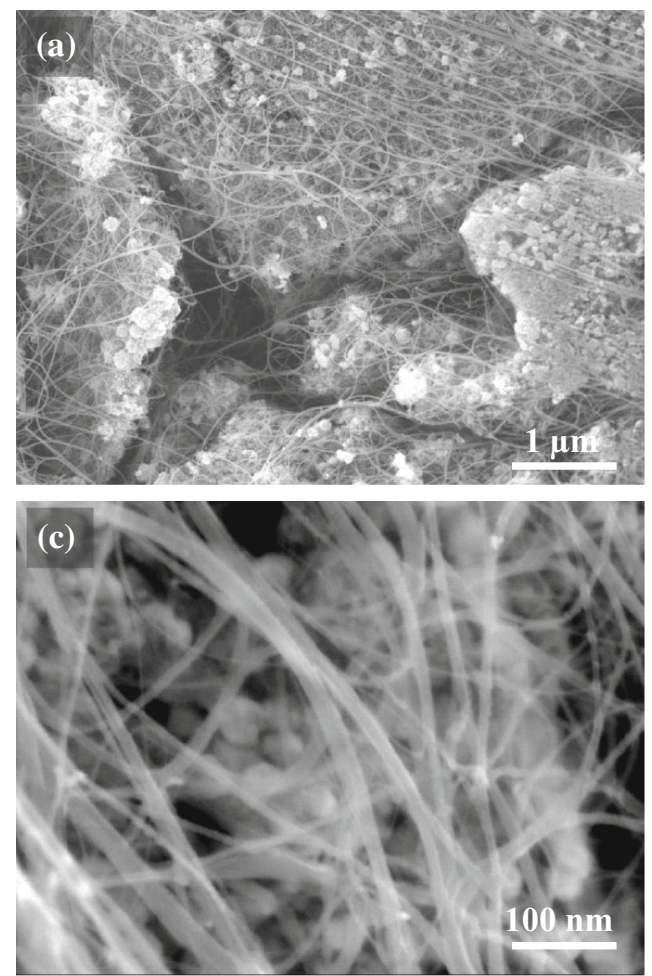

\section{Results and discussion}

\section{Carbon nanotube powders}

The carbon content in powders $\mathrm{AR}$ and $\mathrm{BR}$ is equal to 15.00 and $87.10 \pm 0.02 \mathrm{wt} \%$, respectively. FESEM images of powder AR (Fig. 1a, c) reveal the presence of long, flexible filaments, with a smooth and regular surface, on the surface of the oxide grains and bridging several grains. No thick, short carbon nanofibers are observed. All filaments have a diameter lower than $30 \mathrm{~nm}$ and a length on the order of some tens of micrometers. From the results of previous studies [23, 24, 29], it is known that such filaments are isolated CNTs and/or CNTs bundles. For
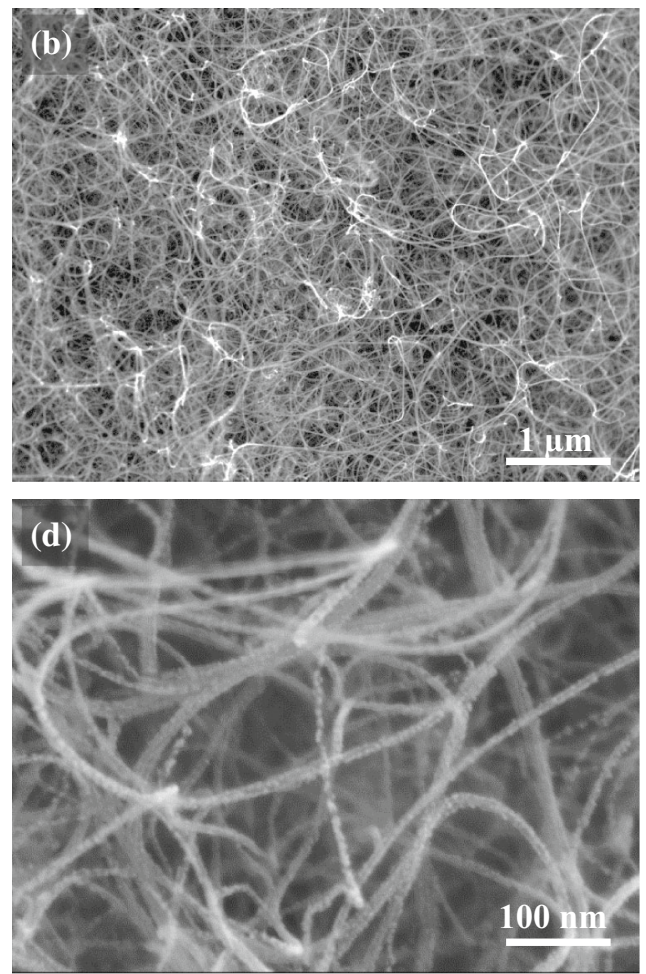

Figure 1 FESEM images of the CNT-Co/Mo-MgO composite powders: $\mathbf{a}, \mathbf{c}$ powder AR and $\mathbf{b}$, $\mathbf{d}$ powder BR.

Table 1 Average number of walls $(N)$, average internal diameter $\left(d_{\text {int }}\right)$, average external diameter $\left(d_{\text {ext }}\right)$ and approximate length $(L)$ of the CNTs, theoretical density of the CNT $\left(\rho_{0}\right)$, carbon content in the CNT samples $\left(\mathrm{C}_{\mathrm{e}}\right)$ (the balance is mostly adsorbed water and residual metal catalyst), Raman $I_{\mathrm{D}} / I_{\mathrm{G}}$ ratio, specific surface area of the CNT samples $\left(S_{\mathrm{BET}}\right)$

\begin{tabular}{lllllllll}
\hline Specimen & $N$ & $d_{\text {int }}(\mathrm{nm})$ & $d_{\text {ext }}(\mathrm{nm})$ & $L(\mu \mathrm{m})$ & $\rho_{0}\left(\mathrm{~g} / \mathrm{cm}^{3}\right)$ & $\mathrm{C}_{\mathrm{e}} \pm 0.2(\mathrm{wt} \%)$ & $I_{\mathrm{D}} / I_{\mathrm{G}}$ & $S_{\mathrm{BET}}\left(\mathrm{m}^{2} / \mathrm{g}\right)$ \\
\hline 3WCNT & 2.7 & 2.1 & 3.5 & $>5$ & 2.09 & 90.5 & 0.08 & 534 \\
4WCNT & 3.6 & 2.6 & 4.6 & $>5$ & 2.06 & 97.3 & 4.16 \\
8WCNT & 8.5 & 5.1 & 10.2 & $<1.5$ & 1.83 & 91.8 & 493 \\
\hline
\end{tabular}


BR (Fig. 1b, d), the CNT bundles are so numerous, in agreement with the high carbon content, that they completely cover the oxide grains. The selective reduction of the starting oxide leads to the formation of nanometric Co particles which immediately catalyze the decomposition of $\mathrm{CH}_{4}$, which is helped by increasing proportions of $\mathrm{MoO}_{3}[24,25]$ and are thus progressively loaded with carbon atoms (activation of the nanoparticles). The carbon concentration in the nanoparticles then increases until reaching the solubility limit, followed by the nucleation and growth of a single CNT on each activated metal particle [30]. It is a complex balance between the relative global proportions of amounts of catalyst ( $\mathrm{Co}$ ), activator $\left(\mathrm{MoO}_{3}\right)$ and carbon source $\left(\mathrm{CH}_{4}\right)$ that determine the local conditions around each activated particle which will in turn determine the number of walls of the corresponding CNT [24, 25, 31-33].

The carbon content in the CNT powders $\left(\mathrm{C}_{\mathrm{e}}-\right.$ Table 1) is equal to $90.5 \mathrm{wt} \%$ for $3 \mathrm{WCNT}, 97.3 \mathrm{wt} \%$ for $4 \mathrm{WCNT}$ and $91.8 \mathrm{wt} \%$ for and the commercial $8 \mathrm{WCNT}$ sample. The balance corresponds mostly to adsorbed water and residual $\mathrm{Co}$ and $\mathrm{Mo}_{2} \mathrm{C}$ particles. The CNT powders were investigated by TEM. Typical images are shown in Fig. 2. The presence of structural defects along the CNT walls and nontubular carbon at their surface may result from degradation under the electron beam, although it is clear that the 8WCNTs (Fig. 2c) contain significantly more defect such as kinks, uncompleted walls, bamboo-like structure and variation of the diameter, along the length of the CNTs. They also are not bundled. The number of walls was measured for about 100 CNTs on HRTEM images. The average number of walls $(\mathrm{N})$ is shown in Table 1. For the 3WCNT specimen (Fig. 3a), CNTs with 1-7 walls are observed. The DWCNTs are dominant $(40 \%)$ with 3WCNTs $(29 \%)$ the second most abundant CNTs. N is equal to 2.7 which was rounded to 3 . For the 4WCNT specimen (Fig. 3b), CNTs with 1-7 walls are also observed but now the 4WCNTs are dominant (30\%) with 3WCNTs (28\%) the second most abundant CNTs. $\mathrm{N}$ is equal to 3.6 which was rounded to 4 . For the 8 WCNT sample (Fig. 3c), CNTs with 3-22 walls are observed. The 8 WCNTs are dominant $(30 \%)$ with 7WCNTs and 9WCNTs (both 16\%) the second most abundant CNTs. $\mathrm{N}$ is equal to 8.5 which was rounded to 8 . The internal and external diameter distribution also derived from HRTEM measurements are shown on the right-side panel of Fig. 3. The average internal
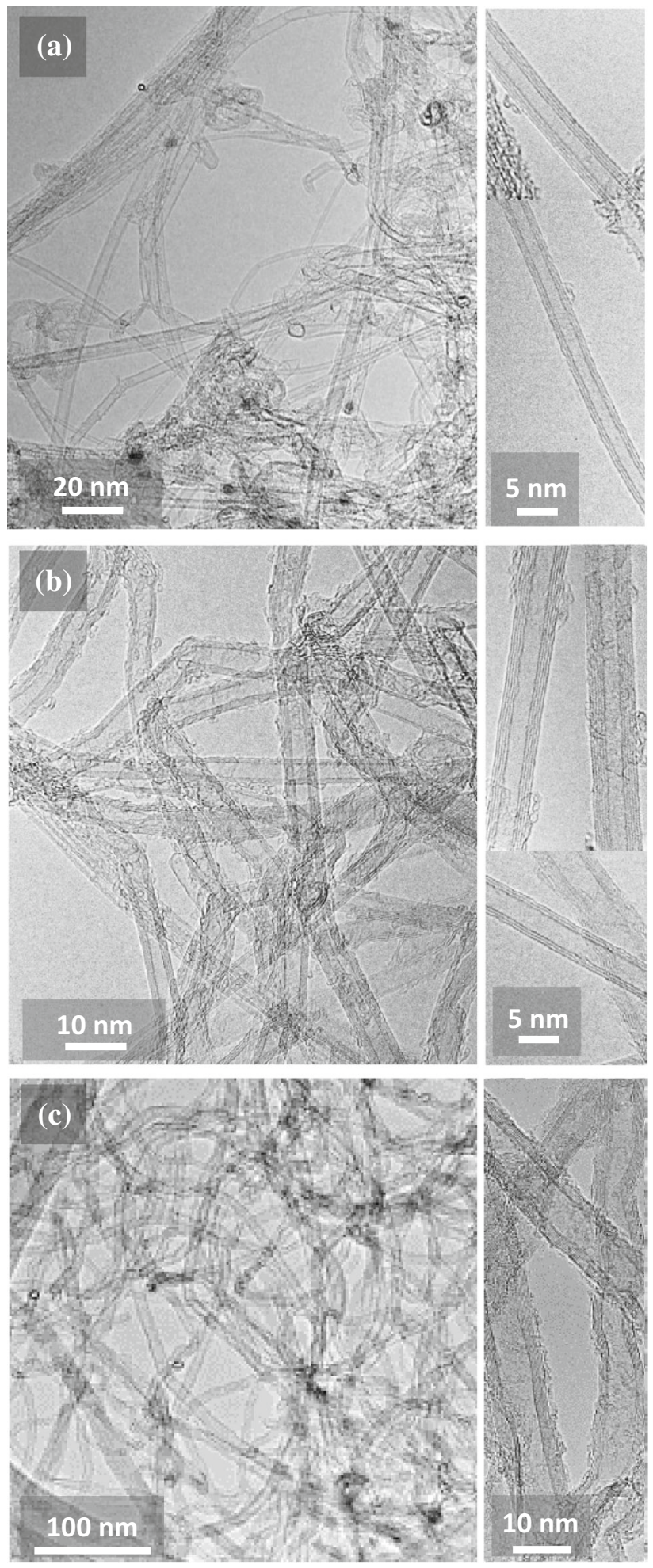

Figure 2 TEM images showing typical CNTs present in the a $3 \mathrm{WCNT}$, b 4WCNT and c 8WCNT samples.

and external diameter $\left(\mathrm{d}_{\mathrm{int}}\right.$ and $\mathrm{d}_{\text {ext }}$-Table 1$)$ are in excellent agreement with the empirical law giving the correlation with $\mathrm{N}$ for a population of MWCNTs 

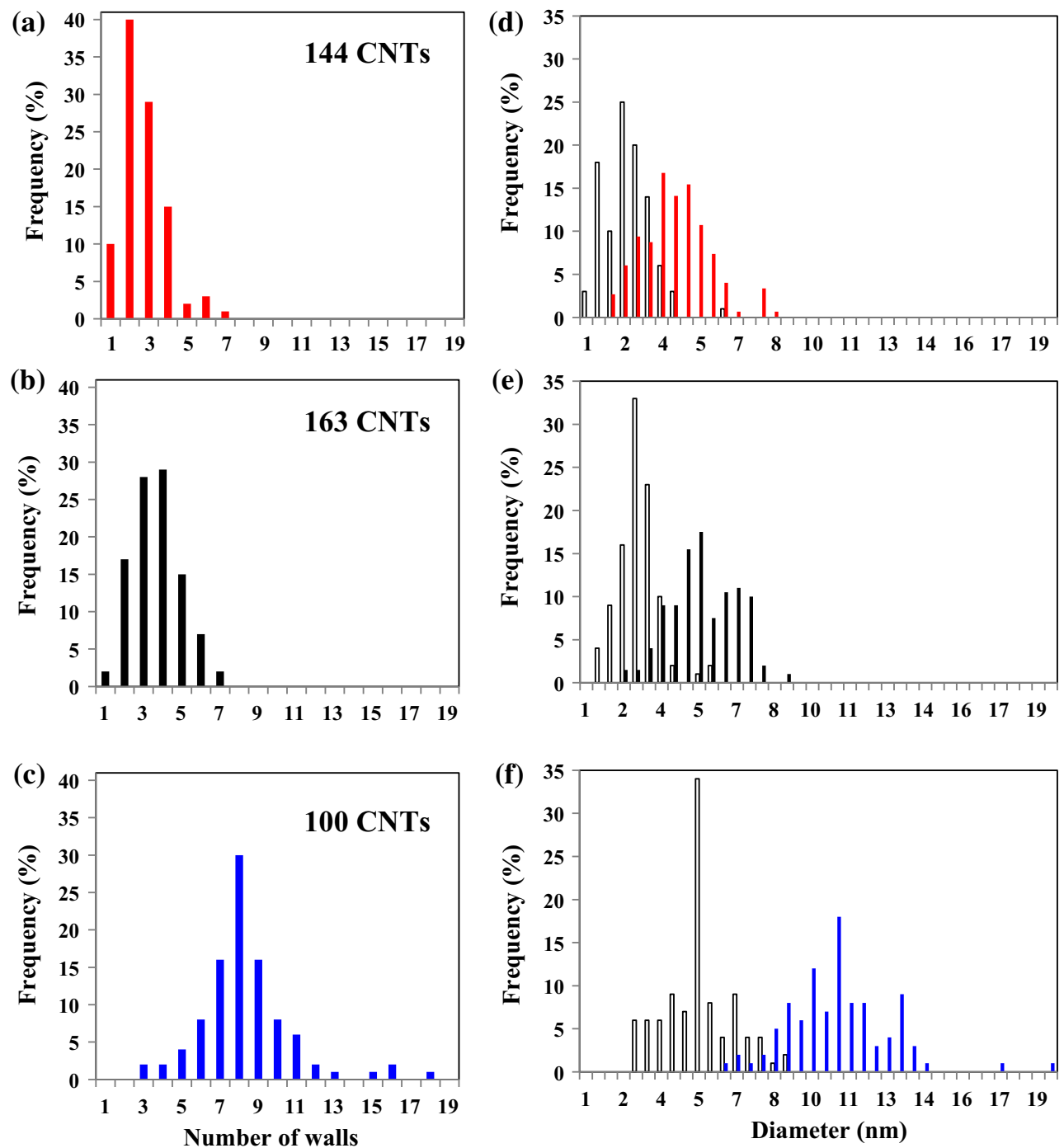

Figure 3 Distribution of the number of walls for the CNTs in the a $3 \mathrm{WCNT}$, b $4 \mathrm{WCNT}$ and $\mathbf{c} 8 \mathrm{WCNT}$ samples; distribution of the internal (open bars) and external (solid bars) diameters for the

CNTs in the $\mathbf{d} 3 \mathrm{WCNT}$, e $4 \mathrm{WCNT}$ and $\mathbf{f} 8 \mathrm{WCNT}$ samples. The number of individual CNTs measured is indicated.

prepared by CCVD [17]. The theoretical density of the CNTs $\left(\rho_{0}\right.$-Table 1$)$ was calculated using the CNT density chart [34]. It was also attempted to evaluate CNT length (L-Table 1) on transmission electron microscopy images, although it is very difficult for the 3WCNT and 4WCNT samples because the CNTs tend to form bundles as noted above.

The Raman spectra of the CNT powders are compared in Fig. 4. $I_{\mathrm{D}} / I_{\mathrm{G}}$ represents the ratio between the intensity of the $D$ band (about $1320 \mathrm{~cm}^{-1}$ ) and the $G$ band (about $1580 \mathrm{~cm}^{-1}$ ). An increasing $I_{\mathrm{D}} / I_{\mathrm{G}}$ value (8, 16 and $190 \%$ for $3 W C N T$, 4 WCNT and $8 W C N T$, respectively) was reported to reflect defective sites or $\mathrm{sp}^{3}$-hybridized carbon atoms [13], accounting for defects in CNT walls and disordered material

surrounding the CNTs [26]. The low-frequency range of the spectra for 3WCNT (Fig. 4a) and 4WCNT (Fig. 4b) shows radial breathing mode (RBM) peaks, indicating the presence of small-diameter CNTs, such as SWCNTs and DWCNTs, in agreement with TEM data (Fig. 3). Note that the Raman process is influenced by optical resonance, and it is thus impossible to detect all present CNTs using only one wavelength. Moreover, the peak intensities do not reflect the real amount of individual CNT because the resonance effect amplifies the Raman signal from certain CNTs.

The CNT powders exhibit a $\mathrm{N}_{2}$ sorption isotherm (Fig. 5 left-side panel) with a narrow hysteresis loop at relative pressures from 0.7 to 1.0 and adsorbed 

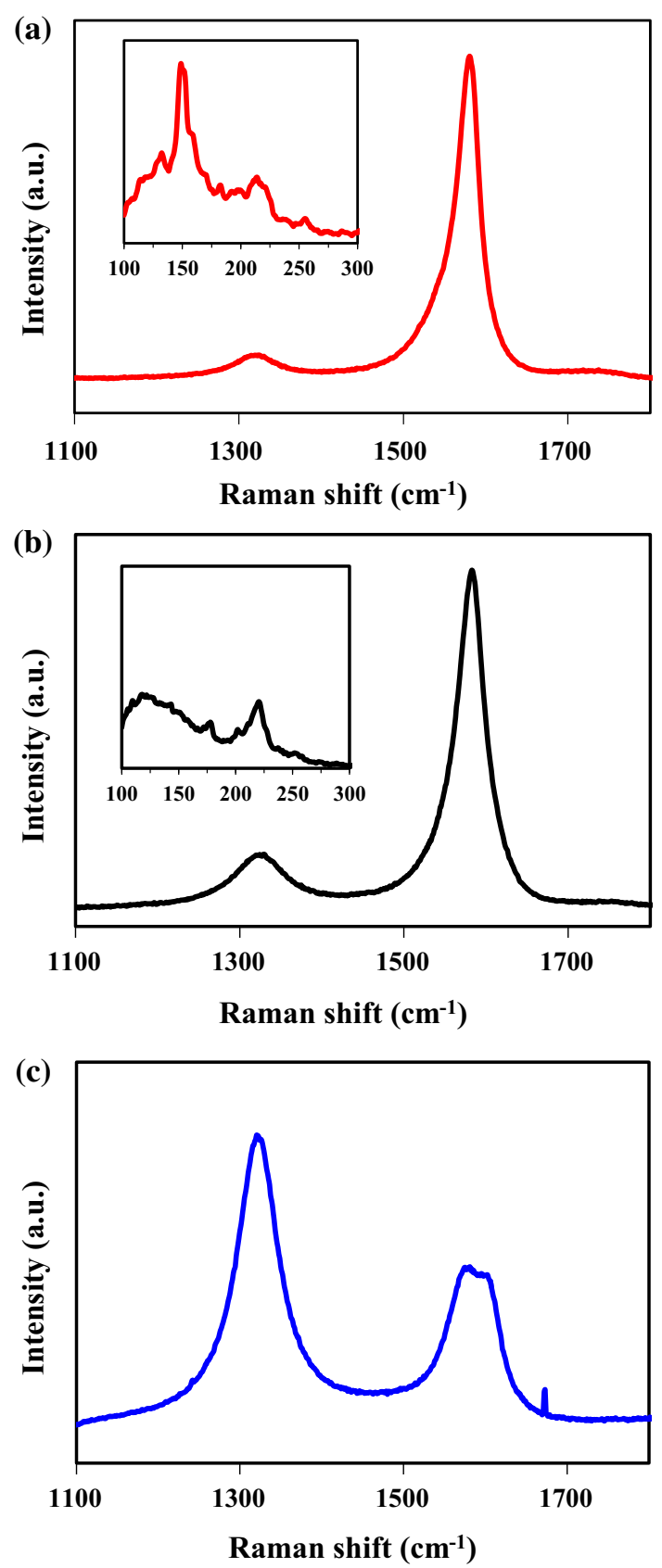

Figure 4 Raman spectra of the a 3WCNT, b 4WCNT and c $8 \mathrm{WCNT}$ samples. Insets are the low-frequency area showing radial breathing mode peaks.

volumes $\left(1000-2500 \mathrm{~m}^{2} / \mathrm{g}\right)$ in line with other reports for thin MWCNTs [35], DWCNTs [15, 36] and SWCNTs [37, 38]. The shape of the isotherm and specifically the presence of the hysteresis loop points to a type IV isotherm, one of the six types of isotherm recognized by the IUPAC classification and characteristic of mesoporous adsorbents (i.e., the pore size diameter is in the range $2-50 \mathrm{~nm}$ ) [39]. Observation of the low-pressure domain (insets in Fig. 5) reveals some microporosity. The mesopore size distributions are very broad (Fig. 5 right-side panel), reflecting mostly the inter-tube space in the specimen $[15,36]$. The BET-specific surface area of the samples $\left(\mathrm{S}_{\mathrm{CNT}}-\right.$ Table 1) decreases upon the increase in number of walls of the CNTs $\left(534,493\right.$ and $242 \mathrm{~m}^{2} / \mathrm{g}$ for $3 \mathrm{WCNT}$, 4WCNT and 8WCNT, respectively), in agreement with calculations from geometrical data (number of walls and diameter) [40].

\section{Carbon nanotube monoliths}

The density ( $\rho$-Table 2 ) of the monoliths increases upon the increase in the SPS temperature. An estimation of the relative density as if the samples were pure carbon, and thus calculated using the theoretical density $\left(\rho_{0}\right.$-Table 1$)$, gives values in the range $45-62 \%$ for 3WCNT, slightly lower (36-53\%) for $4 \mathrm{WCNT}$ and slightly higher (57-70\%) for $8 \mathrm{WCNT}$. The values change only slightly if one takes into account the presence of some residual catalyst as noted above. Both values are nevertheless included in Table 2. Note that no attempt was made to evaluate if the proportion of residual catalyst changed upon SPS. It has been reported [41, 42] that the heat-treatment of the MWCNTs has to be performed at temperatures above $1800{ }^{\circ} \mathrm{C}$ (or $1500{ }^{\circ} \mathrm{C}$ ) to be an efficient method for removing residual metals. The present SPS are performed a temperatures in the range $1000-1500{ }^{\circ} \mathrm{C}$; therefore, any change would be very small. The higher density values for the 8WCNTs could reflect that their shorter length has favored packing. The difference between the 3WCNTs and 4WCNTs could be due to a higher stiffness for the latter. The Raman spectra of the 4WCNT monoliths (Fig. 6) show little change compared to the spectrum of the corresponding 4WCNT powder sample (Fig. 4b). RBM peaks (insets in Fig. 6) are still detected indicating the continuous presence of small-diameter CNTs in all the 4WCNT monoliths. For some samples, 4W1200 (Fig. 6c) and 4W1500 (Fig. 6f), a weak band at $1720 \mathrm{~cm}^{-1}$ is detected. Upon closer inspection, it is present but extremely weak on most spectra including for the $4 \mathrm{WCNT}$ powder (Fig. $4 \mathrm{~b}$ ) and although it is still unclear, it could reflect the presence of disordered carbon due to the influence of the local applied pressure on the different walls, including amorphization, ovalization and collapse [43-45]. The Raman $I_{\mathrm{D}} / I_{\mathrm{G}}$ ratio for the monoliths (Table 2) is 
Figure $5 \quad \mathrm{~N}_{2}$ adsorptiondesorption isotherms $(77 \mathrm{~K})$ for the a $3 \mathrm{WCNT}$, $\mathbf{b} 4 \mathrm{WCNT}$ and c 8WCNT samples (insets show the low-pressure range); pore size distribution as deduced from $\mathrm{N}_{2}$ desorption curves for the CNTs in the d 3 WCNT, e 4WCNT and f 8 WCNT samples.

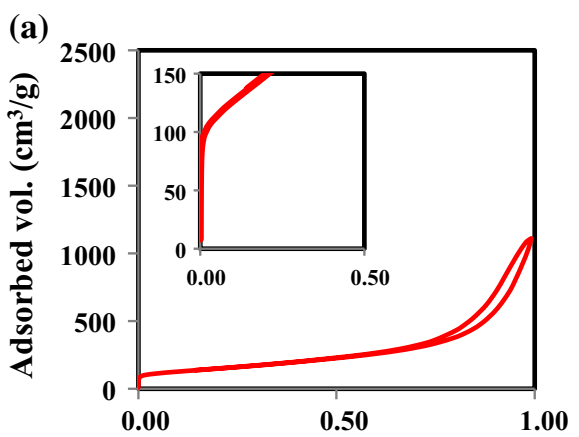

(d)
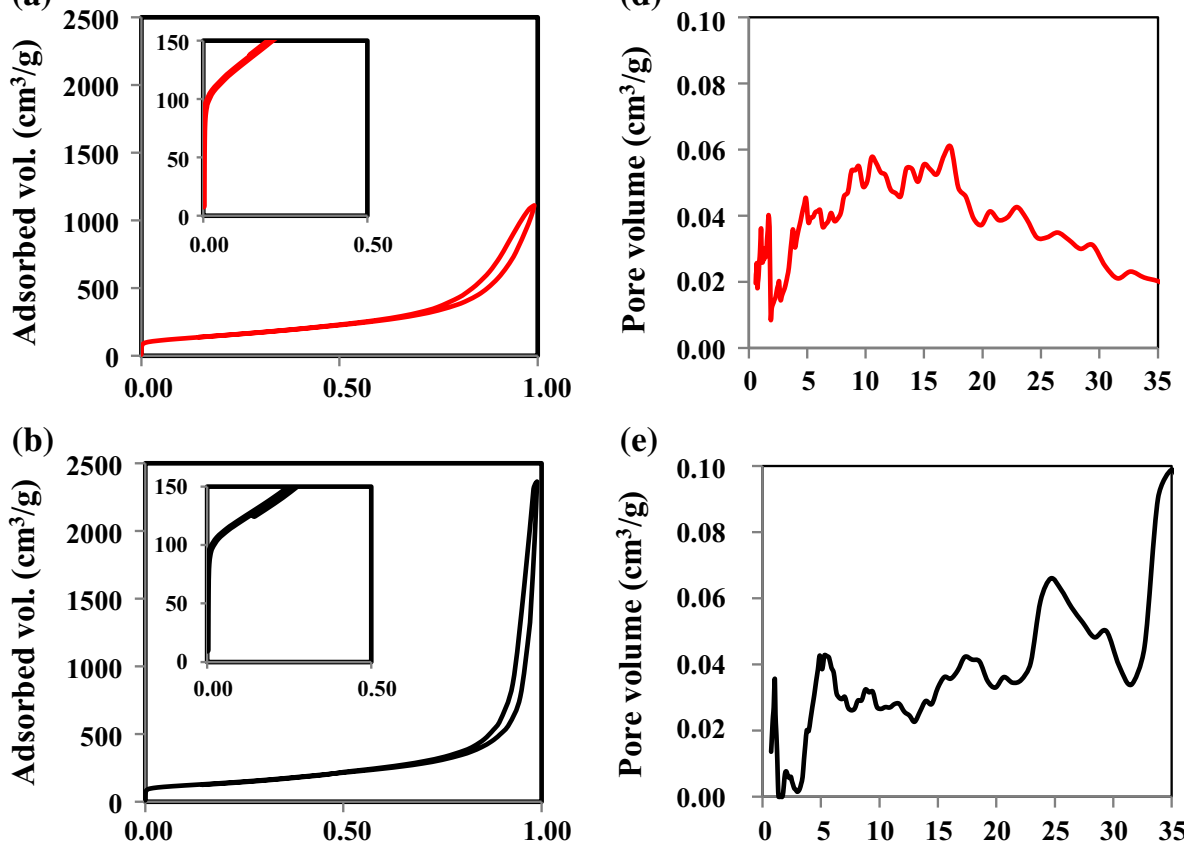

(e)
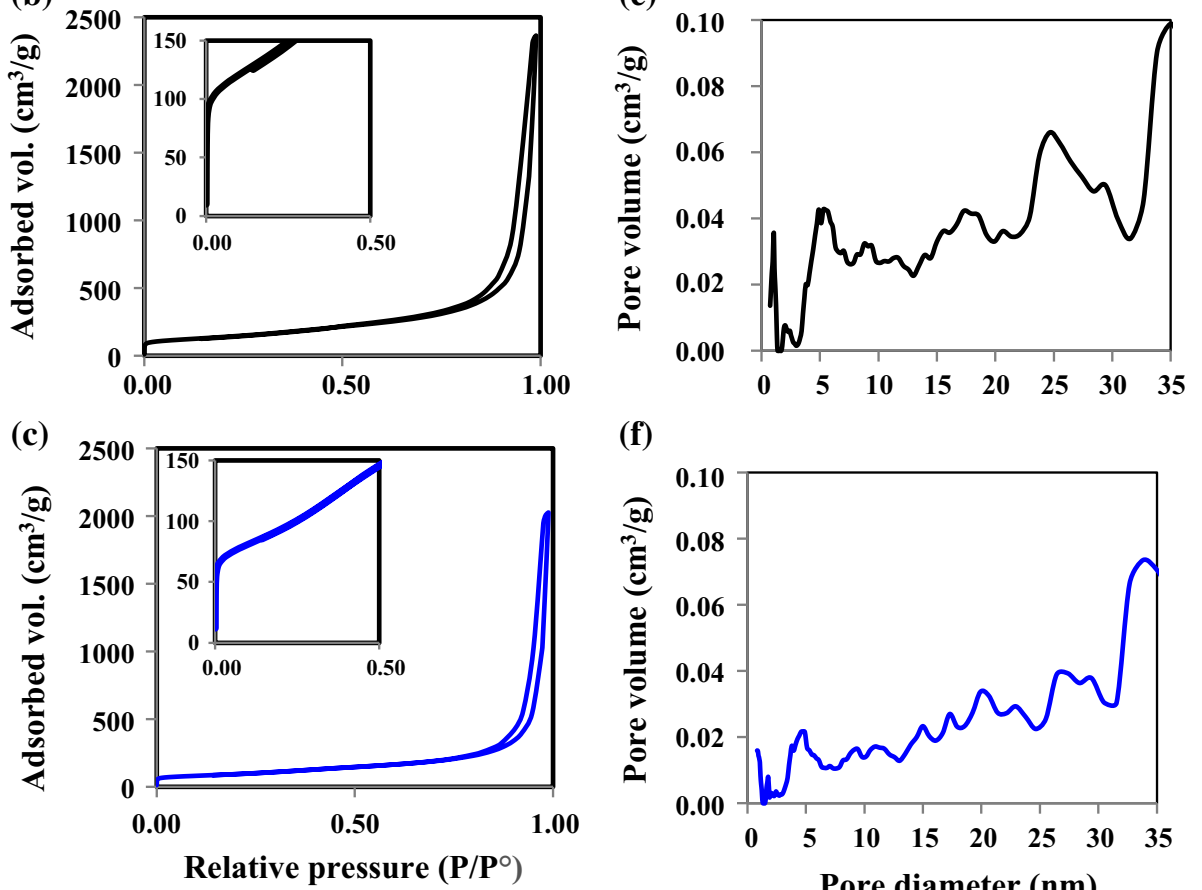

(f)

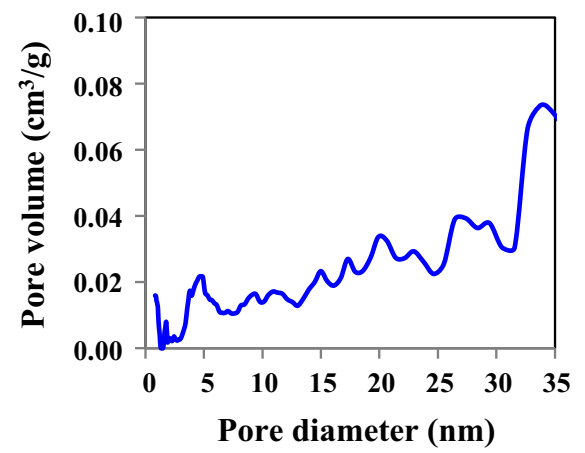

Table 2 Experimental data for the different monoliths: CNT specimen, SPS temperature $\left(T_{\mathrm{SPS}}\right)$, density $(\rho)$, relative density $(d)$, Raman $I_{\mathrm{D}} / I_{\mathrm{G}}$ ratio, specific surface area $\left(S_{\mathrm{BET}}\right)$, porous volume $\left(V_{\mathrm{P}}\right)$

\begin{tabular}{lllllll}
\hline CNT specimen & $T_{\text {SPS }}\left({ }^{\circ} \mathrm{C}\right)$ & $\rho\left(\mathrm{g} / \mathrm{cm}^{3}\right)$ & $d(\%)$ & $I_{\mathrm{D}} / I_{\mathrm{G}}$ & $S_{\mathrm{BET}}\left(\mathrm{m}^{2} / \mathrm{g}\right)$ & $V_{\mathrm{p}}\left(\mathrm{cm}^{3} / \mathrm{g}\right)$ \\
\hline $3 \mathrm{WCNT}$ & 1000 & 1.01 & $45-48$ & 0.05 & 505 & 0.389 \\
$3 \mathrm{WCNT}$ & 1100 & 1.06 & $47-51$ & 0.06 & 538 & 0.390 \\
$3 \mathrm{WCNT}$ & 1200 & 1.15 & $51-55$ & 0.08 & 613 & 0.462 \\
$3 \mathrm{WCNT}$ & 1300 & $1.15-1.22$ & $51-58$ & 0.09 & $401 *$ & - \\
$3 \mathrm{WCNT}$ & 1400 & 1.15 & $51-55$ & 0.09 & $364 *$ & - \\
$3 \mathrm{WCNT}$ & 1500 & 1.30 & $58-62$ & 0.22 & 232 & 0.160 \\
$4 \mathrm{WCNT}$ & 1000 & 0.76 & $36-37$ & 0.08 & 487 & 0.899 \\
$4 \mathrm{WCNT}$ & 1100 & 0.94 & $45-46$ & 0.13 & 484 & 0.734 \\
$4 \mathrm{WCNT}$ & 1300 & 0.97 & $46-47$ & 0.14 & $412 *$ & - \\
$4 \mathrm{WCNT}$ & 1400 & 1.05 & $50-51$ & 0.15 & $402 *$ & - \\
$4 \mathrm{WCNT}$ & 1500 & 1.09 & $52-53$ & 0.20 & 310 & 0.340 \\
$8 \mathrm{WCNT}$ & 1300 & 1.10 & $56-60$ & 1.57 & 214 & 0.264 \\
$8 \mathrm{WCNT}$ & 1400 & 1.17 & $60-64$ & 1.65 & - & - \\
$8 \mathrm{WCNT}$ & 1500 & 1.24 & $63-68$ & 1.51 & - & - \\
$8 \mathrm{WCNT}$ & 1600 & 1.29 & $66-70$ & 1.69 & 211 & 0.213
\end{tabular}

*Date from a one-point measurement (i.e., one adsorption pressure) 
Figure 6 Raman spectra of the 4WCNT monoliths: a 4W1000, b 4W1100, c $4 \mathrm{~W} 1200, \mathrm{~d} 4 \mathrm{~W} 1300$, e $4 \mathrm{~W} 1400$ and $\mathrm{f} 4 \mathrm{~W} 1500$. Insets are the low-frequency area showing radial breathing mode peaks.
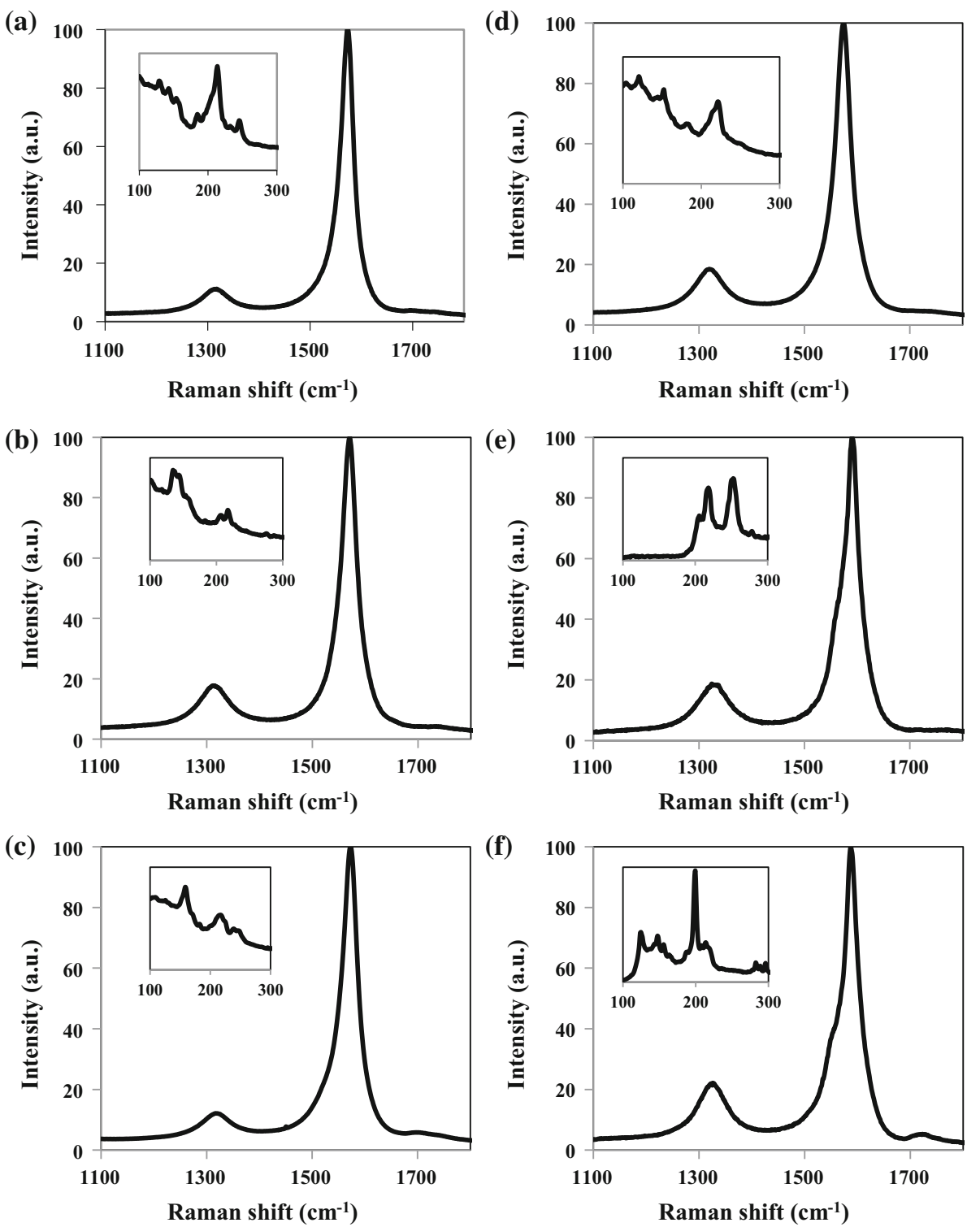

lower than that found prior to consolidation (Table 1), which could reflect the elimination of surface defects and formational defects in the CNT outer walls by a thermal annealing effect during SPS. Indeed, other authors [41, 42, 46] have reported that oxygen functional groups can be selectively removed from a CNT surface and formational defects can anneal out at relatively low temperatures, below $1600{ }^{\circ} \mathrm{C}$, whereas microstructural defects within the MWCNT structure require subsequent annealing at much higher temperatures (typically above $3000{ }^{\circ} \mathrm{C}$ ). The trend, however, is that the $I_{\mathrm{D}} / I_{\mathrm{G}}$ ratio increases upon the increase in temperature and this density (Fig. 7). As mentioned above, this could also reflect the presence of disordered material surrounding the
CNTs [26] and the limited formation of amorphouslike carbon forms during the SPS treatment It has been reported [47] that single-wall CNTs prepared by arc-discharge, with a very narrow diameter distribution (in the range 1.33-1.52 $\mathrm{nm}$ ), are progressively transformed into graphite-like and amorphous-like structures during the SPS process, the latter embedding the remaining CNT bundles. The general evolution should be the same in our case but using CNT samples with a distribution in diameters and number of walls and thus a distribution of defects along their length, any effect is more difficult to observe and anyway the Raman spectra show that the formation of amorphous-like structures during the SPS process is limited. 


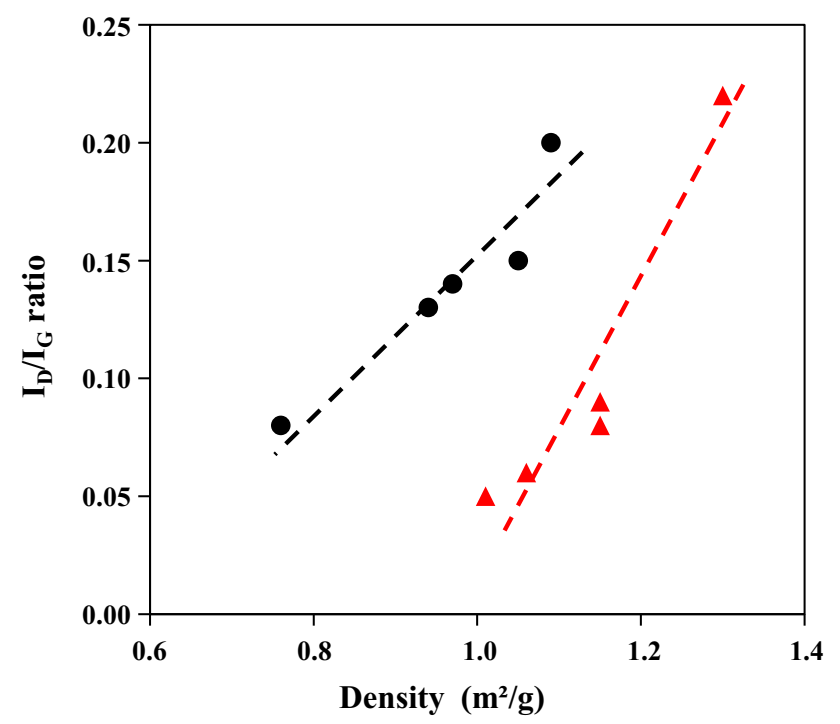

Figure 7 Raman $I_{\mathrm{D}} / I_{\mathrm{G}}$ ratio versus density for the $3 \mathrm{WCNT}$ (triangles) and 4WCNT(circles) monoliths. The dotted lines are guides to the eye.

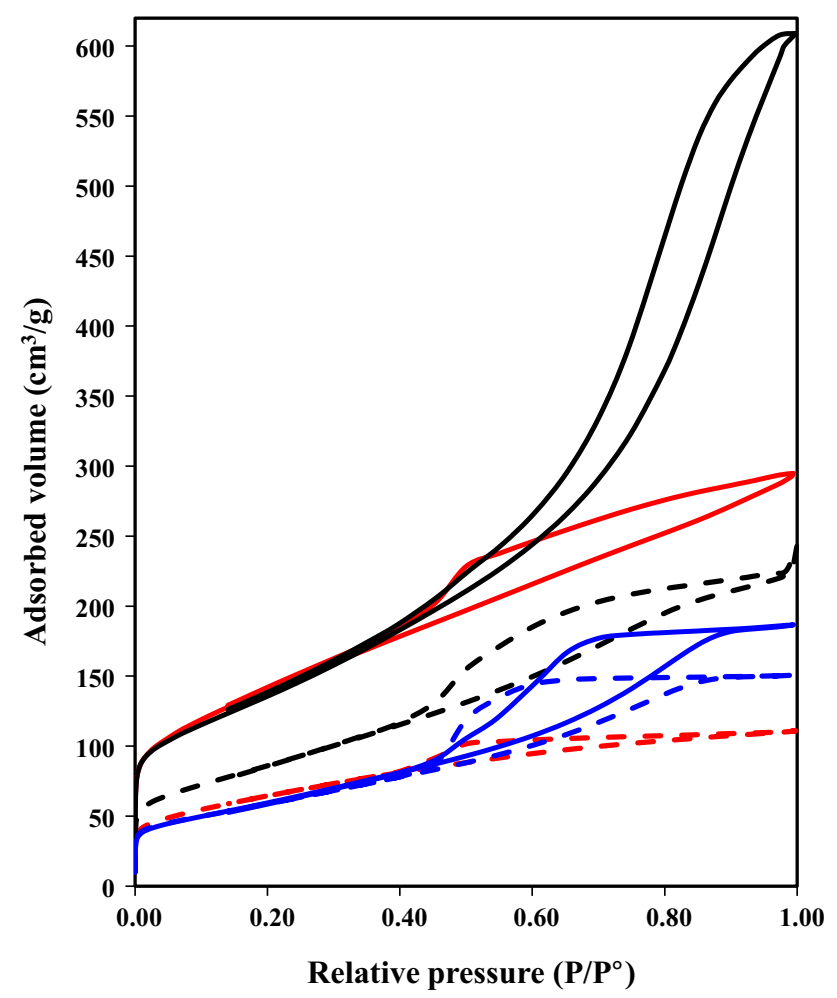

Figure $8 \mathrm{~N}_{2}$ adsorption-desorption isotherms (77 K) for selected monoliths: 3W1000 (solid red), 3W1500 (dotted red), 4W1000 (solid black), 4W1500 (dotted black), 8W1300 (solid blue), 8W1600 (dotted blue).

The CNT sorption isotherms of selected monoliths are presented in Fig. 8. The specific surface area
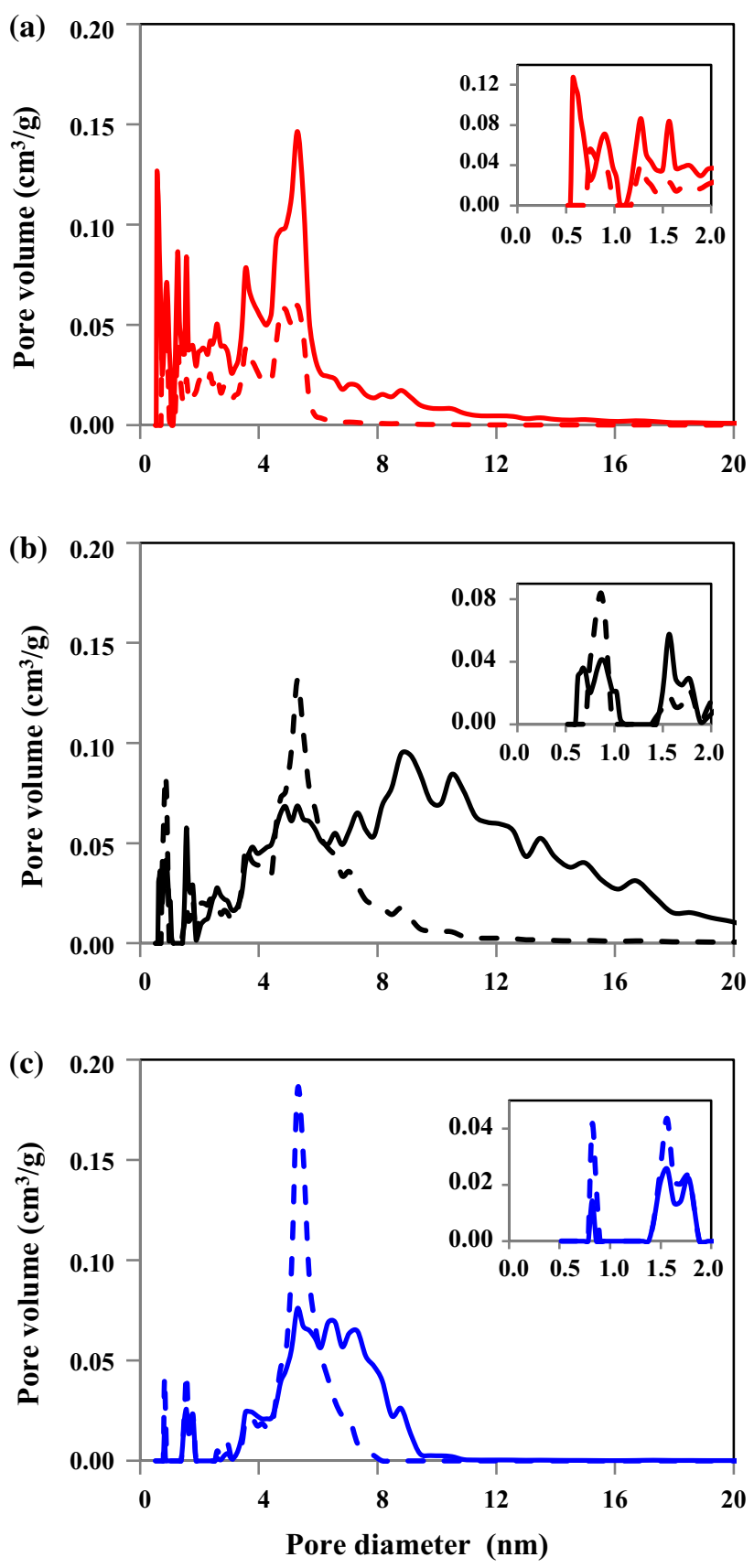

Figure 9 Pore size distribution as deduced from $\mathrm{N}_{2}$ desorption curves for selected monoliths: a 3W1000 (solid red) and 3W1500 (dotted red), b 4W1000 (solid black) and 4W1500 (dotted black), c $8 \mathrm{~W} 1300$ (solid blue) and 8W1600 (dotted blue). Insets show the micropore range.

( $\mathrm{S}_{\mathrm{BET}}$-Table 2) for the 3W monoliths tends to initially slightly increase upon the increase in SPS temperature, from $534 \mathrm{~m}^{2} / \mathrm{g}$ for $3 \mathrm{WCNT}$ to $613 \mathrm{~m}^{2} / \mathrm{g}$ for $3 \mathrm{~W} 1200$, and then regularly decreases. For the $4 \mathrm{~W}$ monoliths, $\mathrm{S}_{\text {BET }}$ stays constant $\left(>480 \mathrm{~m}^{2} / \mathrm{g}\right)$ up to $4 \mathrm{~W} 1200$ and then also regularly decreases down to 
$310 \mathrm{~m}^{2} / \mathrm{g}$ for $4 \mathrm{~W} 1500 . \mathrm{S}_{\mathrm{BET}}$ of $500 \mathrm{~m}^{2} / \mathrm{g}$ was reported for spatially aligned arrays of large (inner diameter equal to $8 \mathrm{~mm}$ ) DWCNTs [36]. For the $8 \mathrm{~W}$ monoliths (ca. $210 \mathrm{~m}^{2} / \mathrm{g}$ ), the decrease compared to the 8WCNT powder $\left(242 \mathrm{~m}^{2} / \mathrm{g}\right)$ is very moderate. The $4 \mathrm{~W} 1000$ isotherm stands out because it still shows a hysteresis loop over a wide range of relative pressure, indicating a wide range of mesopore sizes. It is widely accepted that there is a correlation between the shape of the hysteresis loop and the texture (pore size distribution, pore geometry and connectivity) of a mesoporous material [39]. Moreover, the adsorbed volume (about $600 \mathrm{~cm}^{3} / \mathrm{g}$ ) is markedly higher than for the other monoliths. By contrast, the isotherm for 4W1500, like those for 3W1000, 3W1500, 8W1300 and 8W1600, shows a IUPAC classification H2 loop [39] indicating materials that are often disordered, where the distribution of pore size and shape is not well defined and also indicative of bottleneck constrictions and interconnecting mesopores. The pore size distributions reveal that the $4 \mathrm{~W} 1000$ monolith (solid line in Fig. $9 b$ ) retains mesopores over a wide range from 2 to over $20 \mathrm{~nm}$, whereas the 4W1500 monolith (dotted line in Fig. 9b) and the $3 \mathrm{~W}$ (Fig. 9a) and the $8 \mathrm{~W}$ monoliths (Fig. 9c) have a much narrower pore size distribution, with a maximum diameter at 12,10 or $6 \mathrm{~nm}$ depending on CNT sample and temperature. The fact that other authors $[15,16]$ use the BarrettJoyner-Halenda (BJH) method for calculating the pore size distributions, as opposed to the NLDFT method here, makes it difficult to make comparisons. The BJH method is not fit for pore diameters below $1.7 \mathrm{~nm}$. The volume adsorbed at very low pressure (micropores domain) is similar to that found prior to consolidation and the corresponding pore size distributions (insets in Fig. 9) show two more or less defined micropore ranges, $0.5-1.0 \mathrm{~nm}$ and $1.4-1.9 \mathrm{~nm}$. This could reflect a partial opening of the CNTs [37]. The present values for $S_{\mathrm{BET}}$ and pore size distribution are in line with the values reported for carbon monoliths for non-activated carbon ( $\mathrm{KOH}-$ activation is known to increase the specific surface area and microporosity) and possible applications could be as oil or gas sorbents [16, 48-50]. The porous volume $(V \mathrm{p}$-Table 2$)$ for $4 \mathrm{~W} 1000\left(0.899 \mathrm{~cm}^{3} / \mathrm{g}\right)$ and $4 \mathrm{~W} 1100\left(0.734 \mathrm{~cm}^{3} / \mathrm{g}\right)$ is, however, significantly (2-3 times) higher than for the other present monoliths and those reported elsewhere [16, 49, 50]. Thus, it appears that the 4WCNTs when consolidated into monoliths by SPS at 1000 or $1100{ }^{\circ} \mathrm{C}$ are able to somewhat resist consolidation and to retain some high amount of mesoporosity above $10 \mathrm{~nm}$ which contributes to a high porous volume. Compared to the 3WCNT monoliths with the same $S_{\mathrm{BET}}$ but half the porous volume, this could reflect a particular combination of CNT length, flexibility, proportion of defects as well as sample purity and deserves further studies.

The 4W1500 monolith, with a narrow pores size distribution (dotted line in Fig. 9b), was selected for further characterization. FESEM images of the top surface (Fig. 10b) and cross section (Fig. 10b) reveal undamaged CNTs and CNT bundles. TEM images of the $4 \mathrm{~W} 1500$ thin foil prepared by FIB are presented in Fig. 11. Bundles of 4 WCNT are observed (between the dashed lines in Fig. 11a), indicating that they were not destroyed by FIB milling, therefore validating the method for subsequent TEM observations of CNT monoliths. Interestingly, no pores are
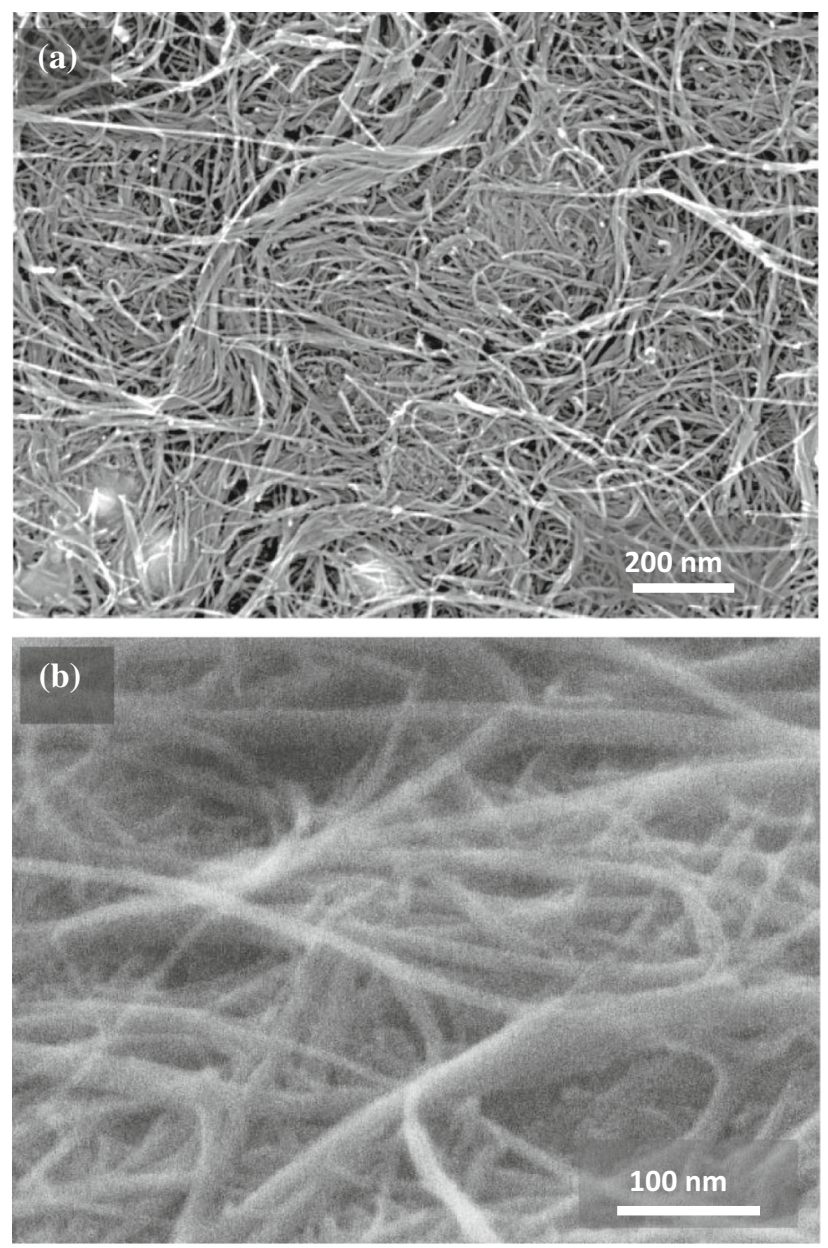

Figure 10 FESEM images of the 4W1500 monolith: a top-view and $\mathbf{b}$ cross-sectional view. 
Figure 11 TEM images of the 4W1500 monolith thin foil showing a bundles of 4WCNT (between the dashed lines) and nanometric particles (dark contrasts arrowed in the boxed area); $\mathbf{b}$ EDS pattern of the corresponding area; $\mathbf{c}$ and d HRTEM images showing reveal pores $2-10 \mathrm{~nm}$ in size, and the cross sections of several FWCNTs. Inset in $\mathbf{d}$ is an electron microdiffraction pattern recorded in an area devoid of nanoparticles.
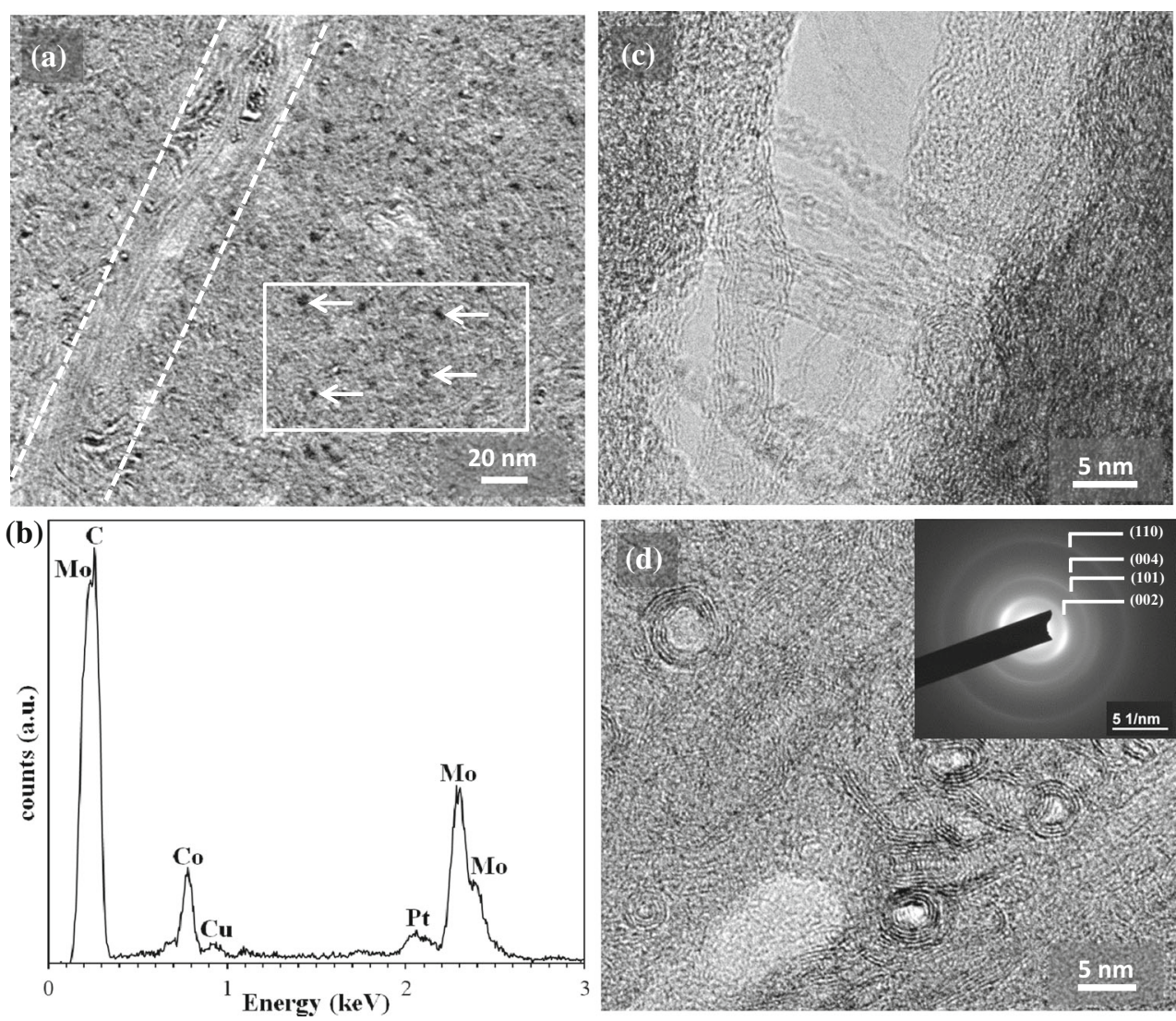

observed at this scale. Nanometric particles are also evidenced (dark contrasts arrowed in Fig. 11a). Analysis of the EDS pattern (Fig. 11b) of the corresponding area reveals the presence of carbon, cobalt and molybdenum elements originating from the CNTs and residual $\mathrm{Co}$ and $\mathrm{Mo}_{2} \mathrm{C}$ catalytic nanoparticles. The detection of copper and platinum reflects the thin foil $\mathrm{Cu}$ support and to the FIB preparation involving a Pt deposit, respectively. Note that EDS is too local a probe for quantitative assessment of the content of residual catalyst in the monolith and, as noted above, that the present SPS temperatures are too low to massively remove the residual metals. HRTEM images (Fig. 11c, d) reveal pores between 2 and $10 \mathrm{~nm}$ in size, in good agreement with the corresponding pore size distribution deduced from the $\mathrm{N}_{2}$ desorption curve (2-12 nm, dotted line in Fig. 9b). The cross sections of several FWCNTs are clearly observed (Fig. 11d), but it is not possible to prove that they are open and contribute to the porosity. An electron microdiffraction pattern (inset in Fig. 11d) recorded in an area devoid of nanoparticles presents four rings corresponding to the (002), (101), (004) and
(110) planes of graphite, reflecting the spatial disorganization of the 4WCNTs within the monolith.

\section{Summary and conclusions}

Carbon nanotubes with few walls (FWCNTs) are prepared by catalytic chemical vapor deposition. The average number of walls (3, 4 and 8$)$ and the internal and external diameter distributions are determined from TEM images. The 3WCNTs and 4WCNTs prepared in-house show less defects than the commercial 8WCNTs. Binder-free FWCNTs monoliths are prepared by spark plasma sintering of the CNT powders at $1000-1600{ }^{\circ} \mathrm{C}$. The high temperatures favor the elimination of surface defects of the FWCNT, although there is a progressive albeit limited amorphization upon the increase in SPS temperature. No dramatic damage to the CNTs is detected by FESEM and HRTEM observations. Densification increases moderately upon the increase in SPS temperature and most monoliths show a density close to about $1 \mathrm{~cm}^{3} / \mathrm{g}$. 
$\mathrm{N}_{2}$ adsorption-desorption cycles revealed that the powders and monoliths show microporosity and, mostly, mesoporosity. The 3WCNT and 4WCNT monoliths sintered at 1000 and $1100{ }^{\circ} \mathrm{C}$ show a specific surface area equal to about $500 \mathrm{~m}^{2} / \mathrm{g}$, with very little losses compared to the corresponding powders. Interestingly, the $4 \mathrm{WCNT}$ monoliths are able to retain a high amount of mesoporosity in the 10-20 $\mathrm{nm}$ range and thus they show a high porous volume of the order of $0.8 \mathrm{~cm}^{3} / \mathrm{g}$, twice the value reported found for other CNT monoliths or foams. The difference between the 3WCNTs and 4WCNTs could reflect a particular combination of CNT length, flexibility and proportion of defects and warrants further studies.

\section{Acknowledgements}

The authors thank Ch. Chauvin for CNT synthesis and test samples preparation. Electron microscopy was performed at "Centre de microcaractérisation Raimond Castaing-UMS 3623" (Toulouse) and the authors thank C. Josse and A. Descamps-Mandine for FIB preparation and help with the TEM observations. The SPS was performed at the Plateforme Nationale CNRS de Frittage-Flash ( $\mathrm{PNF}^{2}$, Toulouse). This work is made in part under the contract ANR 2011-NANO025 TRI-CO.

\section{References}

[1] Ma RZ, Xu CL, Wei BQ, Liang J, Wu DH, Li DJ (1999) Electrical conductivity and field emission characteristics of hot-pressed sintered carbon nanotubes. Mater Res Bull 34:741-747

[2] Zhang HL, Li JF, Yao KF, Chen LD (2005) Spark plasma sintering and thermal conductivity of carbon nanotube bulk materials. J Appl Phys 97:114310-1-114310-4

[3] Qin C, Shi X, Bai SQ, Chen LD, Wang LJ (2006) High temperature electrical and thermal properties of the bulk carbon nanotube prepared by SPS. Mater Sci Eng A 420:208-211

[4] Yang K, He J, Su Z, Reppert JB, Skove MJ, Tritt TM, Rao $\mathrm{AM}$ (2010) Inter-tube bonding, graphene formation and anisotropic transport properties in spark plasma sintered multi-wall carbon nanotube arrays. Carbon 48:756-762
[5] Zhang HL, Lia JF, Yao KF, Chen LD (2005) Spark plasma sintering and thermal conductivity of carbon nanotube bulk materials. J Appl Phys 97:114310-1-114310-4

[6] Marinho B, Ghislandi M, Tkalya E, Koning CE, de With G (2012) Electrical conductivity of compacts of graphene, multi-wall carbon nanotubes, carbon black, and graphite powder. Powder Technol 221:351-358

[7] Cha SI, Kim KT, Lee KH, Mo CB, Jeong YJ, Hong SH (2008) Mechanical and electrical properties of cross-linked carbon nanotubes. Carbon 46:482-488

[8] Li JL, Bai GZ, Feng JW, Jiang W (2005) Microstructure and mechanical properties of hot-pressed carbon nanotubes compacted by spark plasma sintering. Carbon 43:2649-2653

[9] Li JL, Wang LJ, He T, Jiang W (2007) Surface graphitization and mechanical properties of hot-pressed bulk carbon nanotubes compacted by spark plasma sintering. Carbon 45:2636-2642

[10] Yamamoto G, Sato Y, Takahashi T, Omori M, Okubo A, Tohji K, Hashida T (2006) Mechanical properties of binderfree single-walled carbon nanotubes solids. Scr Mater 54:299-303

[11] Wang W, Yokoyama A, Liao S, Omori M, Zhu Y, Uo M, Akasaka T, Watari F (2008) Preparation and characteristics of a binderless carbon nanotube monolith and its biocompatibility. Mater Sci Eng C 28:1082-1086

[12] Uo M, Hasegawa T, Akasaka T, Tanaka I, Munekane F, Omori M, Kimura H, Nakatomi R, Soga K, Kogo Y, Watari F (2009) Multiwalled carbon nanotube monoliths prepared by spark plasma sintering (SPS) and their mechanical properties. Bio-Med Mater Eng 19:11-17

[13] Sato Y, Nishizaka H, Sawano S, Yoshinaka A, Hirano K, Hashiguchi S, Arie T, Akita S, Yamamoto G, Hashida T, Kimura H, Motomiya K, Tohji K (2012) Influence of the structure of the nanotube on the mechanical properties of binder-free multi-walled carbon nanotube solids. Carbon 50:34-39

[14] Amadou J, Begin D, Nguyen P, Tessonnier JP, Dintzer T, Vanhaecke E, Ledoux MJ, Pham-Huu C (2006) Synthesis of a carbon nanotube monolith with controlled macroscopic shape. Carbon 44:2587-2592

[15] Laurent Ch, Chevallier G, Weibel A, Peigney A, Estournès C (2008) Spark plasma sintering of double-walled carbon nanotubes. Carbon 46:1812-1816

[16] Liu YF, Ba H, Nguyen DL, Ersen O, Romero T, Zafeiratos S, Begin D, Janowska I, Pham-Huu C (2013) Synthesis of porous carbon nanotubes foam composites with a high accessible surface area and tunable porosity. J Mater Chem A 1:9508-9516

[17] Chiodarelli N, Richard O, Bender H, Heyns M, De Gendt S, Groeseneken G, Vereecken PM (2012) Correlation between 
number of walls and diameter in multiwall carbon nanotubes grown by chemical vapor deposition. Carbon 50:1748-1752

[18] Preston C, Song D, Taillon J, Cumings J, Hu L (2016) Boron-doped few-walled carbon nanotubes: novel synthesis and properties. Nanotechnology 27:445601-1-445601-9

[19] Jeong HJ, Kim KK, Jeong SY, Park MH, Yang CW, Lee YH (2004) High-yield catalytic synthesis of thin multiwalled carbon nanotubes. J Phys Chem B 108:17695-17698

[20] Lukic B, Seo JW, Bacsa RR, Delpeux S, Béguin F, Bister G, Fonseca A, Nagy JB, Kis A, Jeney S, Kulik AJ, Forro L (2005) Catalytically grown carbon nanotubes of small diameter have a high Young's modulus. Nano Lett 5:2074-2077

[21] Qian C, Qi H, Gao B, Cheng Y, Qiu Q, Zhou O, Liu JJ (2006) Fabrication of small diameter few-walled carbon nanotubes with enhanced field emission property. J Nanosci Nanotechnol 6:1346-1349

[22] Hou Y, Tang J, Zhang HB, Qian C, Feng YY, Liu J (2009) Functionalized few-walled carbon nanotubes for mechanical reinforcement of polymeric composites. ACS Nano 3:1057-1062

[23] Flahaut E, Peigney A, Bacsa WS, Bacsa RR, Laurent Ch (2004) CCVD synthesis of carbon nanotubes from (Mg Co, Mo)O catalysts: influence of the proportions of cobalt and molybdenum. J Mater Chem 14:646-653

[24] Flahaut E, Laurent Ch, Peigney A (2005) Catalytic CVD synthesis of double and triple-walled carbon nanotubes by the control of catalyst preparation. Carbon 43:375-383

[25] Flahaut E, Peigney A, Laurent Ch, Rousset A (2000) Synthesis of single-walled carbon nanotubes - $\mathrm{Co}-\mathrm{MgO}$ composite powders and extraction of the nanotubes. J Mater Chem 10:49-52

[26] Osswald S, Flahaut E, Gogotsi Y (2005) Elimination of D-band in Raman spectra of double-wall carbon nanotubes by oxidation. Chem Phys Lett 402:422-427

[27] Bortolamiol T, Lukanov P, Galibert AM, Soula B, Lonchambon P, Datas L, Flahaut E (2014) Double-walled carbon nanotubes: quantitative purification assessment, balance between purification and degradation and solution filling as an evidence of opening. Carbon 78:79-90

[28] Guiderdoni Ch, Pavlenko E, Turq V, Weibel A, Puech P, Estournès C, Peigney A, Bacsa W, Laurent Ch (2013) The preparation of carbon nanotube (CNT)/copper composites and the effect of the number of CNT walls on their hardness, friction and wear properties. Carbon 58:185-197

[29] Flahaut E, Peigney A, Laurent C (2003) Double-walled carbon nanotubes in composite powders. J Nanosci Nanotechnol 3:151-158
[30] Peigney A, Laurent Ch, Dobigeon F, Rousset A (1997) Carbon nanotubes grown in situ by a novel catalytic method. J Mater Res 12:613-615

[31] Cordier A, de Resende VG, Weibel A, De Grave E, Peigney A, Laurent Ch (2010) Catalytic chemical vapor deposition synthesis of double-walled and few-walled carbon nanotubes by using a $\mathrm{MoO}_{3}$-supported conditioning catalyst to control the formation of iron catalytic particles within a $\alpha-\mathrm{Al}_{1.8-}$ $\mathrm{Fe}_{0.2} \mathrm{O}_{3}$ self-supported foam. $J$ Phys Chem C 114:19188-19193

[32] Kasperski A, Weibel A, Datas L, De Grave E, Peigney A, Laurent Ch (2015) Large-diameter single-wall carbon nanotubes formed alongside small-diameter double-walled carbon nanotubes. J Phys Chem C 119:1524-1535

[33] Zhang Q, Yu H, Liu Y, Qian W, Wang Y, Luo G, Wei F (2008) Few walled carbon nanotube production in largescale by nano-agglomerate fluidized-bed process. NANO 3:45-50

[34] Laurent Ch, Flahaut E, Peigney A (2010) The weight and density of carbon nanotubes versus the number of walls and diameter. Carbon 48:2994-2996

[35] Kim DY, Yang CM, Park YS, Kim KK, Jeong SY, Han JH, Lee YH (2005) Characterization of thin multi-walled carbon nanotubes synthesized by catalytic chemical vapor deposition. Chem Phys Lett 413:135-141

[36] Babu DJ, Lange M, Cherkashinin G, Issanin A, Staudt R, Schneider JJ (2013) Gas adsorption studies of $\mathrm{CO}_{2}$ and $\mathrm{N}_{2}$ in spatially aligned double-walled carbon nanotube arrays. Carbon 61:616-623

[37] Yang CM, Kaneko K, Yudasaka M, Iijima S (2002) Effect of purification on pore structure of HiPco single-walled carbon nanotube aggregates. Nano Lett 2:385-388

[38] $\mathrm{Hu} \mathrm{YH}$, Ruckenstein E (2004) Pore size distribution of single-walled carbon nanotubes. Ind Eng Chem Res 43:708-711

[39] Sing KSW, Everett DH, Haul RAW, Moscou L, Pierotti RA, Rouquerol J, Siemieniewska T (1985) Reporting physisorption data for gas/solid systems with special reference to the determination of surface area and porosity. Pure Appl Chem 57:603-619

[40] Peigney A, Laurent Ch, Flahaut E, Bacsa RR, Rousset A (2001) Specific surface area of carbon nanotubes and bundles of carbon nanotubes. Carbon 39:507-514

[41] Andrews R, Jacques D, Qian D, Dickey EC (2001) Purification and structural annealing of multiwalled carbon nanotubes at graphitization temperatures. Carbon 39:1681-1687

[42] Huang W, Wang Y, Luo G, Wei F (2003) 99.9\% purity multiwalled carbon nanotubes by vacuum high-temperature annealing. Carbon 41:2585-2590 
[43] Goncharov AF, Andreev VD (1991) Raman scattering in carbon films at high pressures. Sov Phys JETP 73:140-142

[44] Aguiar AL, Capaz RB, Souza Filho AG, San-Miguel A (2012) Structural and phonon properties of bundled singleand double-wall carbon nanotubes under pressure. J Phys Chem C 116:22637-22645

[45] Puech P, Hubel H, Dunstan DJ, Bacsa RR, Laurent C, Bacsa WS (2004) Discontinuous tangential stress in doublewall carbon nanotubes. Phys Rev Lett 93:095506-1-095506-4

[46] Baaziz W, Begin-Colin S, Pichon BP, Florea I, Ersen O, Zafeiratos S, Barbosa R, Begin D, Pham-Huu C (2012) High density monodisperse cobalt nanoparticles (NPs) filling of multi-walled carbon nanotubes. Chem Mater Commun 24:1549-1551
[47] Yamamoto G, Sato Y, Takahashi T, Omori M, Hashida T, Okubo A, Tohji K (2006) Single-walled carbon nanotubederived novel structural material. J Mater Res 21:1537-1542

[48] Du R, Zhao Q, Zhang N, Zhang J (2015) Macroscopic carbon nanotube-based 3D monoliths. Small 11:3263-3289

[49] Klepel O, Danneberg N, Dräger M, Erlitz M, Taubert M (2016) Synthesis of porous carbon monoliths using hard templates. Materials 9:1-14

[50] Gupta J, Tai NH (2016) Carbon materials as oil sorbent: a review on the synthesis and performance. J Mater Chem A 4:1550-1565 